\title{
Vasorelaxation Effect of Estrone Derivate EA204 in Rabbit Aorta
}

\author{
Juan Li, ${ }^{1,2}$ Wei-Qi Li, ${ }^{3,4}$ and Yao Yao ${ }^{5,6}$ \\ ${ }^{1}$ School of Pharmacy, Ningxia Medical University, Yinchuan 750004, China \\ ${ }^{2}$ Ningxia Engineering and Technology Research Center for Modernization of Hui Medicine, Yinchuan 750004, China \\ ${ }^{3}$ National Resource Center of Chinese Materia Medica, China Academy of Chinese Medical Sciences, Beijing 100700, China \\ ${ }^{4}$ China National Center for Biotechnology Development, Beijing 100039, China \\ ${ }^{5}$ School of Basic Medical Science, Ningxia Medical University, Yinchuan 750004, China \\ ${ }^{6}$ Research Center of Medical Science and Technology, Ningxia Medical University, Yinchuan 750004, China
}

Correspondence should be addressed to Yao Yao; 79569506@qq.com

Received 1 December 2015; Revised 13 March 2016; Accepted 27 March 2016

Academic Editor: Antonio Cano

Copyright (C) 2016 Juan Li et al. This is an open access article distributed under the Creative Commons Attribution License, which permits unrestricted use, distribution, and reproduction in any medium, provided the original work is properly cited.

Estrogen and its derivatives exert vascular protective effects, but the underlying mechanisms remain to be studied fully. Objective. To investigate the vasorelaxation effect and related mechanisms of an estrone derivate EA204[3-(2-piperidin-1-yl)-ethoxy-estra-1, 3, 5 (10)-trien-17-one] on isolated arterial preparation from rabbit thoracic aorta. Methods. Aortic rings from rabbit thoracic aorta were prepared and held in small organ bath filled with Krebs solution; tension change was recorded by a multichannel physiological signal collection and handling system. Results. EA204 $\left(10^{-5}\right.$ to $\left.10^{-3} \mathrm{M}\right)$ induced a concentration-dependent relaxation of aortic rings with endothelium and without endothelium. In denuded arterial preparations, EA204 had a potent relaxing effect on isolated arterial preparations contracted with phenylephrine, norepinephrine, and high- $\mathrm{K}^{+}$solution or $\mathrm{BaCl}_{2} \cdot \mathrm{Mechanism}$ study indicates that EA204 relaxes aortic rings by inhibiting $\mathrm{Ca}^{2+}$ channels (both receptor-operating $\mathrm{Ca}^{2+}$ channels and the voltage-dependent $\mathrm{Ca}^{2+}$ channels were involved) to decrease extracellular $\mathrm{Ca}^{2+}$ influx and intracellular $\mathrm{Ca}^{2+}$ release. EA204 is different from verapamil, which is a noncompetitive inhibitor of $\mathrm{Ca}^{2+}$ channels. In addition, $\mathrm{K}^{+}$channels opening may contribute to this vasorelaxation effect. Conclusion. EA204 had a potent endothelium-independent relaxing effect on isolated arterial preparation by inhibiting Ca ${ }^{2+}$ channels and opening $\mathrm{K}^{+}$channels. The results suggest that EA204 is a potential compound for treatment of cardiovascular diseases in postmenopausal women.

\section{Introduction}

It is widely accepted that the low incidence of cardiovascular mortality and morbidity in women can be ascribed to differences in their hormonal status compared to men. Moreover, cessation of ovarian hormones after menopause is known to increase susceptibility to vascular dysfunction such as atherosclerosis [1] and possibly hypertension [2]. Thus, many leading health organizations recommended the use of hormone therapy (HT) for the primary prevention of cardiovascular disorders. Although the results from the Women's Health Initiative (WHI) showed that the health risks (particularly cardiovascular diseases and breast cancer) associated with HT were significantly larger than the health benefits [3], which led to a rapid decrease in HT use worldwide, many scientists have different opinion. For example, a recent long-term follow-up study carried out in Finland revealed that HT could significantly reduce the risk of death caused by coronary heart disease (CHD) or stroke [4], suggesting estrogen as a possible medical source to treat cardiovascular diseases in postmenopausal women.

Considering the serious side effects and untoward reactions of natural estrogen, it is reasonable and necessary to synthesize new estrogen derivatives for treatment. Vasorelaxation induced by estrogen and derivatives may be either endothelium-dependent or endothelium-independent $[5,6]$. Estrogen receptor has been reported to play a key role in endothelium-dependent vasorelaxation $[7,8]$. But the mechanism of endothelium-independent vasorelaxation induced by estrogen remains to be understood fully. For this purpose, we prepared a number of estrone derivatives and tested their relaxing effect. In these 24 estrone derivates 


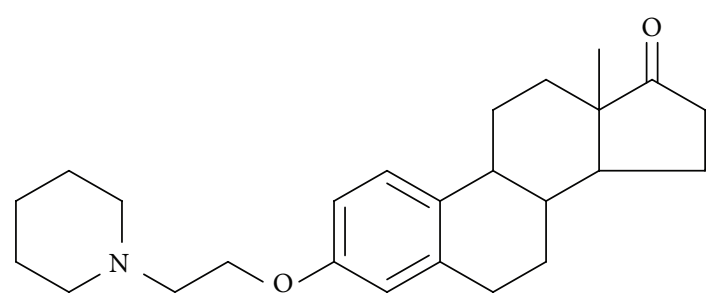

FIgURE 1: Chemical structure of EA204.

EA204[3-(2-piperidin-1-yl)-ethoxy-estra-1, 3, 5 (10)-trien-17one] (Figure 1) had the strongest relaxing effect. Here we report the relaxing effect of EA204 on isolated arterial preparation from rabbit thoracic aorta and discuss possible mechanism of endothelium-independent vasorelaxation.

\section{Methods}

2.1. Animals, Solutions, and Drugs. New Zealand rabbits of both sexes $(2.0 \sim 2.5 \mathrm{~kg})$ were obtained from the Experimental Animal Center of Ningxia Medical University. All animal experiments in this study were approved by the Ethics Committee of Ningxia Medical University.

A modified Krebs solution with the following ionic composition (mM) was used [9]: $\mathrm{NaCl}$ (121.9), $\mathrm{KCl}$ (4.7), $\mathrm{MgCl}_{2}$ (1.2), $\mathrm{CaCl}_{2}$ (2.5), $\mathrm{NaHCO}_{3}$ (15.5), $\mathrm{KH}_{2} \mathrm{PO}_{4}$ (1.2), and glucose (11.5). The $\mathrm{pH}$ of the solution was adjusted to 7.3-7.4 with $5 \% \mathrm{CO}_{2}: 95 \% \mathrm{O}_{2}$. All solutions were stored at $-4^{\circ} \mathrm{C}$ and fresh dilutions were made daily. These drugs were dissolved in distilled water.

EA204 was provided by Pharmaceutical Engineering College, Shenyang Pharmaceutical University. Phenylephrine, norepinephrine, and acetylcholine were purchased from Sigma-Aldrich Inc. (St. Louis, MO, USA). $\mathrm{KCl}$ was from Shenyang Chemical Reagent Factory, China. $\mathrm{CaCl}_{2}$ was from Tianjin Bodi Chemical Co., China. $\mathrm{BaCl}_{2}$ was from Shenyang Xingdong Reagent Factory, China. Verapamil injection was from Tianjing Heping Pharmaceutical Co., China. Glibenclamide was from Beijing Taiyang Pharmaceutical Co., China. Sodium pentobarbital was from Beijing Chemical Reagents Co., China.

\subsection{Preparations of the Aorta Rings and Assessment of Vascular} Function. Rabbits were killed by overdose of sodium pentobarbital $(25 \mathrm{mg} / \mathrm{kg})$ injected via the ear vein. The thoracic aortas were dissected and isolated by removing the surrounding connective tissue. They were cut into rings $(3 \mathrm{~mm})$ and were mounted between two stainless-steel triangles in a small organ bath containing $10 \mathrm{~mL}$ Krebs solution $\left(37^{\circ} \mathrm{C}\right)$, aerated with $95 \% \mathrm{O}_{2}$ and $5 \% \mathrm{CO}_{2}$, one of which was fixed to the organ bath and the other to a force displacement transducer (Chengdu Instrument Plant). Isometric tension change was recorded by RM6240B Multichannel Physiological Signal Collection and Handling System (Chengdu Instrument Plant). Each preparation was stretched to an initial tension of $1 \mathrm{~g}$ [10] and allowed to equilibrate in warmed Krebs solution $\left(37^{\circ} \mathrm{C}\right)$ for $1 \mathrm{~h}$.
The effects of EA204 on the rings with intact or denuded endothelium have been examined. In order to test the endothelium-independent vasorelaxation induced by EA204, endothelium was mechanically removed by rubbing with a steel wire. Aortic rings were precontracted with phenylephrine $(1 \mu \mathrm{M})$ and then acetylcholine $(20 \mu \mathrm{M})$ was added into the organ bath to determine whether the aorta was intact or denuded. If the maximal relaxant effect was more than $80 \%$ of initial contraction, we considered functional endothelium to be present. Failure of arteries to relax to acetylcholine was considered to indicate denuded aorta [11]. Then the concentration-response curves of EA204 were obtained as the following protocol: (1) following $1 \mathrm{~h}$ equilibration, the aortic preparations were precontracted with phenylephrine $(1 \mu \mathrm{M})$; (2) after the contraction had reached a stable plateau, the strips were washed by Krebs solution and 30 min later the strips were precontracted again; (3) when a stable contraction was obtained, the cumulative concentrations of EA204 $\left(10^{-5}\right.$ to $\left.10^{-3} \mathrm{M}\right)$ were added and relaxation produced by each concentration of EA204 was measured and expressed as a percentage of the maximum possible relaxation (i.e., relaxation back to the baseline tension). In other three groups, the experiments were repeated with norepinephrine $(3 \mu \mathrm{M})$, high- $\mathrm{K}^{+}(60 \mathrm{mM})$, and $\mathrm{BaCl}_{2}(2 \mathrm{mg} / \mathrm{mL})$, respectively.

To investigate how EA204 affects $\mathrm{Ca}^{2+}$ channels, verapamil, a noncompetitive calcium antagonist, was used to compare with EA204. After $1 \mathrm{~h}$ equilibration, the aortic preparations were incubated in a $\mathrm{Ca}^{2+}$-free Krebs solution for $30 \mathrm{~min}$ and then in a high- $\mathrm{K}^{+}$and $\mathrm{Ca}^{2+}$-free Krebs solution for $20 \mathrm{~min}$. After that, $\mathrm{CaCl}_{2}$ was added in a cumulative fashion $\left(10^{-6}\right.$ to $\left.10^{-2} \mathrm{M}\right)$ to obtain control concentrationresponse curves of $\mathrm{Ca}^{2+}$. Then, rings were washed by Krebs solution and equilibrated for $1 \mathrm{~h}$. Following the incubation of EA204 $\left(10^{-5} \mathrm{M}\right)$ for $20 \mathrm{~min}$, the concentration-response curves of $\mathrm{Ca}^{2+}$ were repeated. Verapamil $\left(10^{-7} \mathrm{M}\right)$ was used to compare with EA204 as a noncompetitive inhibitor of $\mathrm{Ca}^{2+}$ channels.

To determine whether $\mathrm{K}^{+}$channels are involved, the affection of glibenclamide on the vasorelaxation effect of EA204 was investigated. After $1 \mathrm{~h}$ equilibration, the isolated preparations were precontracted with $\mathrm{BaCl}_{2}(2 \mathrm{mg} / \mathrm{mL})$ or $\mathrm{KCl}(60 \mathrm{mM})$. After the contraction had reached a stable plateau, EA204 was added in a cumulative fashion $\left(10^{-5}\right.$ to $10^{-3} \mathrm{M}$ ) to obtain control concentration-response curves of EA204. Then, the isolated preparations were washed by Krebs solution and equilibrated for $1 \mathrm{~h}$. Following the incubation of glibenclamide $\left(10^{-5} \mathrm{M}\right)$ for $10 \mathrm{~min}$, the concentrationresponse curves of EA204 were repeated [12].

2.3. Statistical Analysis. The data are presented as the means \pm SEM for the number of experiments indicated; $n$ refers to the number of preparations from different animals used.

\section{Results}

The effects of EA204 on the rings with intact or denuded endothelium were examined. Results have shown that EA204 $\left(10^{-5}\right.$ to $\left.10^{-3} \mathrm{M}\right)$ induced a concentration-dependent relaxation of rings with endothelium and without endothelium 


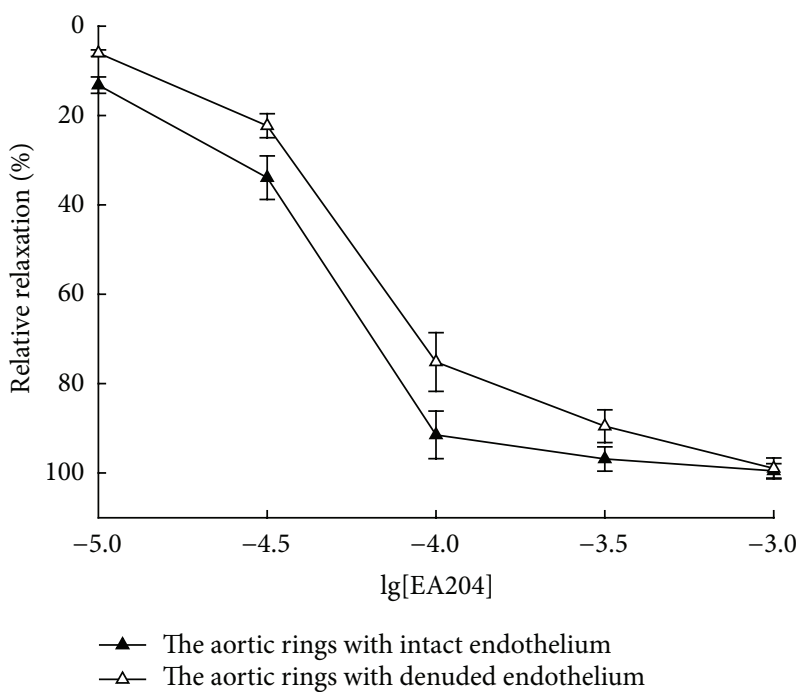

FIGURE 2: Concentration-response curves for EA204 in rabbit aorta with and without endothelium. Aortic rings were precontracted with phenylephrine $(1 \mu \mathrm{M})$. Endothelium was removed mechanically by rubbing with a steel wire. Responses are expressed as a percentage of the maximum possible relaxation, that is, relaxation back to the baseline tension. Values indicated the means $\pm \operatorname{SEM}(n=8)$.

(as shown in Figure 2). Low concentration EA204 $\left(10^{-5}\right.$ to $3 \times 10^{-4} \mathrm{M}$ ) induced a weaker relaxation in denuded aorta, but the maximal responses were identical under high concentration $\left(10^{-3} \mathrm{M}\right)$ condition.

To investigate endothelium-independent vasorelaxation effect of EA204, denuded aortic rings from rabbit thoracic aorta were prepared and tension changes were recorded. The results indicated that administration of EA204 induced relaxation of the isolated aorta preparations precontracted with phenylephrine, norepinephrine, high- $\mathrm{K}^{+}$, or $\mathrm{BaCl}_{2}$, and the maximum relaxant effect was found in rings precontracted with phenylephrine (as shown in Figure 3).

To investigate whether EA204 affects $\mathrm{Ca}^{2+}$ channels, we did experiments to compare EA204 with verapamil, which is a noncompetitive calcium antagonist. Increasing concentration of $\mathrm{CaCl}_{2}\left(10^{-6}\right.$ to $\left.10^{-2} \mathrm{M}\right)$ resulted in concentrationdependent contraction of the isolated aorta of rabbits. Both EA204 and verapamil could shift the concentrationresponse curves of $\mathrm{CaCl}_{2}$ to the right, and the rightward shifts were concentration-dependent. It suggested that EA204 and verapamil inhibited voltage-dependent $\mathrm{Ca}^{2+}$ channels and decreased $\mathrm{Ca}^{2+}$ influx. However, after incubation with verapamil the maximum responses of the cumulative concentration-response curves were significantly decreased, while EA204 did not affect the maximum responses (as shown in Figure 4). The results indicate that, different from verapamil, EA204 is not a noncompetitive calcium antagonist.

To determine whether $\mathrm{K}^{+}$channels are involved, we investigated the affection of glibenclamide on the vasorelaxation effect of EA204. Glibenclamide is a $\mathrm{K}^{+}$channels antagonist which could selectively block ATP sensitive

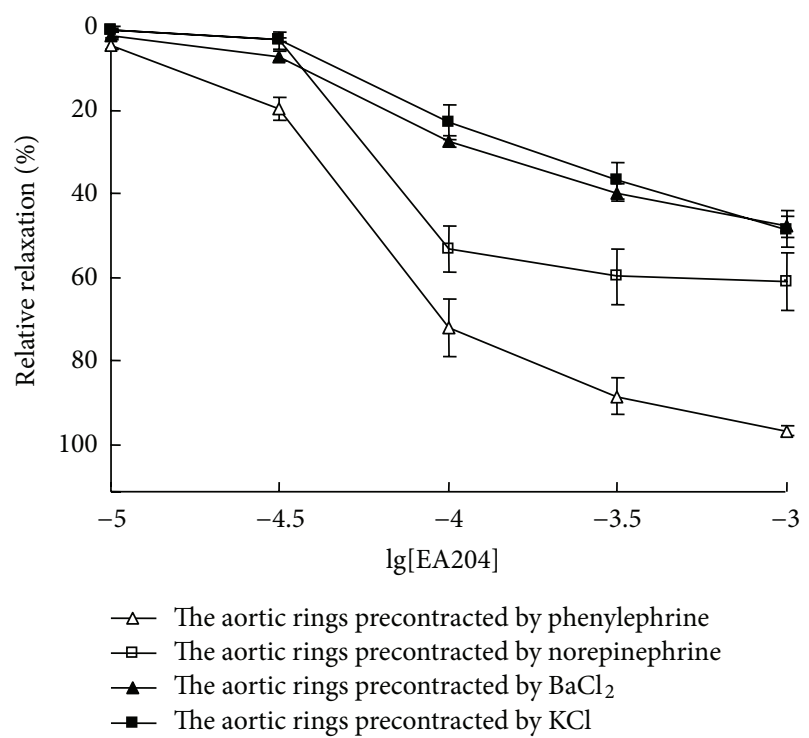

FIGURE 3: Endothelium-independent vasorelaxant effects of EA204 on denuded aortic rings of rabbits precontracted by phenylephrine $(1 \mu \mathrm{M})$, norepinephrine $(3 \mu \mathrm{M})$, high- $\mathrm{K}^{+}$solution $(60 \mathrm{mM})$, and $\mathrm{BaCl}_{2}(2 \mathrm{mg} / \mathrm{mL})$, respectively. Endothelium was removed mechanically by rubbing with a steel wire. Responses are expressed as a percentage of the maximum possible relaxation, that is, relaxation back to the baseline tension. Values indicated the means \pm SEM $(n=8)$.

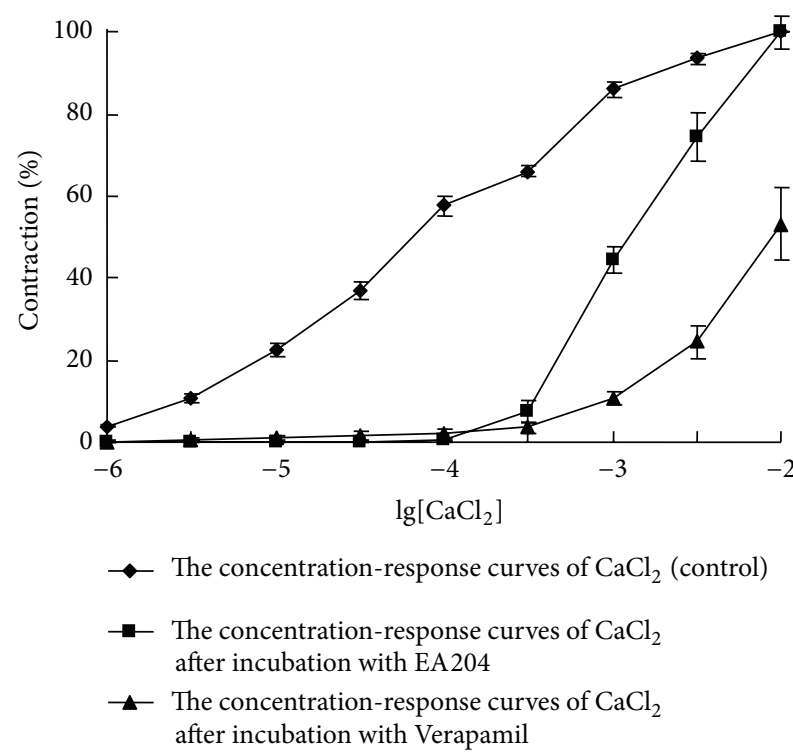

FIgURE 4: Inhibitory activities of EA204 $(10 \mu \mathrm{M})$ and verapamil $(0.1 \mu \mathrm{M})$ on the concentration-response curves of $\mathrm{CaCl}_{2}\left(10^{-6}\right.$ to $10^{-2} \mathrm{M}$ ) on denuded aortic rings of rabbits. Endothelium was removed mechanically by rubbing with a steel wire. Responses are expressed as a percentage of the maximum contraction induced by $\mathrm{CaCl}_{2}\left(10^{-2} \mathrm{M}\right)$. Values indicated the means $\pm \operatorname{SEM}(n=8)$.

$\mathrm{K}^{+}$channels to increase extracellular $\mathrm{Ca}^{2+}$ influx. It was found that the vasorelaxation effect of EA204 was significantly decreased after the incubation of glibenclamide (as shown in Figures 5 and 6). The results indicate that 


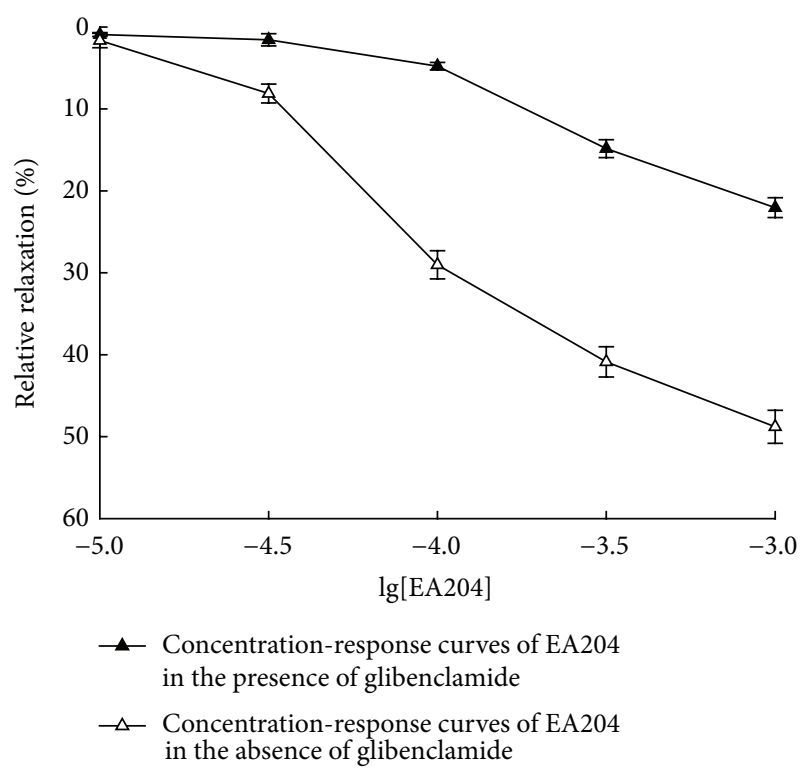

FIGURE 5: Cumulative concentration-response curves of EA204 in the absence or presence of glibenclamide $\left(10^{-5} \mathrm{M}\right)$ on denuded aortic rings of rabbits precontracted with $\mathrm{BaCl}_{2}(2 \mathrm{mg} / \mathrm{mL})$. Endothelium was removed mechanically by rubbing with a steel wire. Responses are expressed as a percentage of the maximum possible relaxation, that is, relaxation back to the baseline tension. Values indicated the means $\pm \operatorname{SEM}(n=8)$.

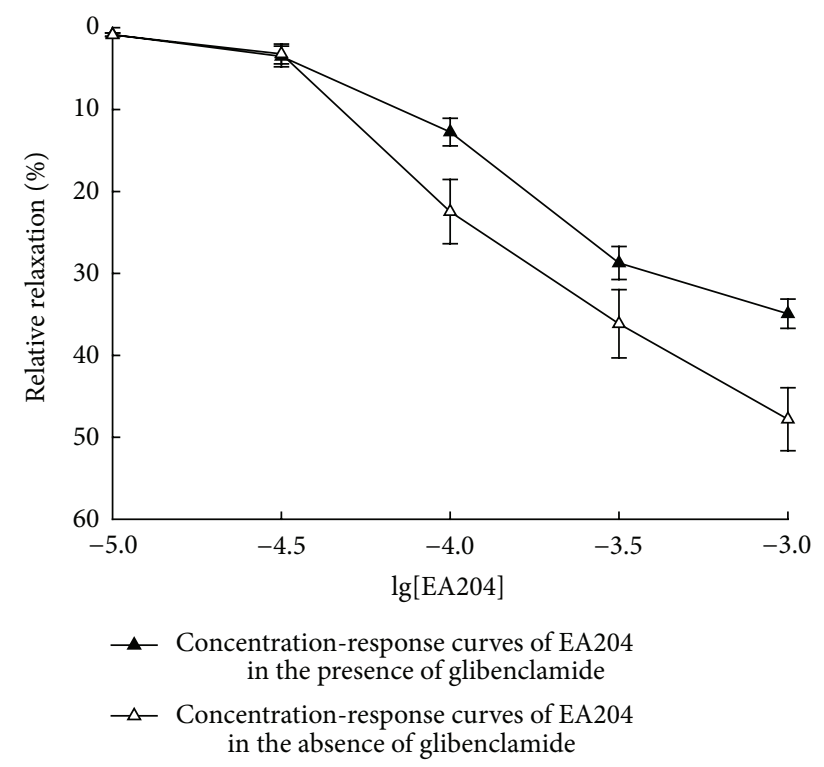

FIGURE 6: Cumulative concentration-response curves of EA204 in the absence or presence of glibenclamide $\left(10^{-5} \mathrm{M}\right)$ on denuded aortic rings of rabbits precontracted with $\mathrm{KCl}(60 \mathrm{mM})$. Endothelium was removed mechanically by rubbing with a steel wire. Responses are expressed as a percentage of the maximum possible relaxation, that is, relaxation back to the baseline tension. Values indicated the means $\pm \operatorname{SEM}(n=8)$.

$\mathrm{K}^{+}$channels opening may contribute to the vasorelaxation effect of EA204.

\section{Discussion}

The cardiovascular protective activity of estrogen is reported to be mediated by an effect on the vessel wall itself directly and an indirect effect on the lipoprotein metabolism. Recently, researchers have made numerous efforts to understand estrogen's cardiovascular actions, especially in its endothelial mechanisms $[13,14]$. For example, $17 \beta$-estradiol has been shown to augment endothelium-dependent vasodilation [15], promote endothelial integrity $[16,17]$, and attenuate the inflammatory response in endothelium [18]. However, the endothelium-independent mechanisms are far from being understood.

In smooth muscle cells, there are two major kinds of $\mathrm{Ca}^{2+}$ channels: the voltage-dependent $\mathrm{Ca}^{2+}$ channels and receptoroperated $\mathrm{Ca}^{2+}$ channels. Phenylephrine and norepinephrine cause vasoconstriction by opening receptor-operated calcium channels $[19,20]$. High- $\mathrm{K}^{+}$solution can excite voltagedependent $\mathrm{Ca}^{2+}$ channels and increase extracellular $\mathrm{Ca}^{2+}$ influx; $\mathrm{BaCl}_{2}$ causes the depolarization of the cell membrane and intracellular $\mathrm{Ca}^{2+}$ release; moreover, $\mathrm{BaCl}_{2}$ can transit the cell membrane through the $\mathrm{Ca}^{2+}$ channels to bind with troponin directly. Researchers have demonstrated that the relaxant effect of $17 \beta$-estradiol on human saphenous vein was elicited by calcium-dependent pathways [21]. Consistent with previous study, our results suggested that EA204 had a potent relaxation effect in endothelium-independent way, and this effect may be associated with the $\mathrm{Ca}^{2+}$ channels.

In order to know more about the relationship between relaxation effect of EA204 and $\mathrm{Ca}^{2+}$ channels, a noncompetitive calcium antagonist verapamil was used to compare with EA204. $\mathrm{CaCl}_{2}$ was added in a cumulative fashion to obtain control concentration-response curves of $\mathrm{Ca}^{2+}$. As reported before, increasing concentration of $\mathrm{CaCl}_{2}$ resulted in concentration-dependent contraction of the isolated aorta [19]. Moreover, both EA204 and verapamil shifted the concentration-response curves of $\mathrm{CaCl}_{2}$ to the right, and the effects were dose dependent. The results suggested that EA204 and verapamil inhibited voltage-dependent $\mathrm{Ca}^{2+}$ channels and decreased $\mathrm{Ca}^{2+}$ influx. However, after incubation with verapamil, the maximum responses of the cumulative concentration-response curves to $\mathrm{CaCl}_{2}$ were significantly decreased, which were not affected after incubation with EA204. The result indicates that, different from verapamil, EA204 is not a noncompetitive calcium antagonist.

Glibenclamide is a $\mathrm{K}^{+}$channels antagonist, which can selectively block ATP sensitive $\mathrm{K}^{+}$channels to increase extracellular $\mathrm{Ca}^{2+}$ influx [22]. $\mathrm{K}^{+}$channels are usually involved in the relaxing effect; thus we investigated the effect of glibenclamide on EA204 induced vasorelaxation to discuss if $\mathrm{K}^{+}$channels are responsible for this effect. We found that the vasorelaxation effect of EA204 was significantly decreased after the incubation of glibenclamide. The results indicate that $\mathrm{K}^{+}$channels opening is involved in the mechanisms of vasorelaxation effect.

Taken together, the endothelium-independent vasorelaxant action and underlying mechanism of estrone derivate EA204 in rabbit aorta were elucidated for the first time in 
this study. The mechanism includes the inhibition of $\mathrm{Ca}^{2+}$ influx through voltage-dependent or receptor-operated $\mathrm{Ca}^{2+}$ channels, the inhibition of intracellular $\mathrm{Ca}^{2+}$ release, and the opening of $\mathrm{K}^{+}$channels. These data suggest that EA204 is a potential compound to be used for the treatment of cardiovascular diseases in postmenopausal women.

\section{Competing Interests}

The authors declare that they have no competing interests.

\section{Acknowledgments}

This work was supported by the Research Project of Ningxia Medical University [Grant no. XM200710].

\section{References}

[1] S. P. Glasser, A. P. Selwyn, and P. Ganz, "Atherosclerosis: risk factors and vascular endothelium," American Heart Journal, vol. 131, no. 2, pp. 379-384, 1996.

[2] J. A. Staessen, H. Celis, and R. Fagard, "The epidemiology of the association between hypertension and menopause," Journal of Human Hypertension, vol. 12, no. 9, pp. 587-592, 1998.

[3] J. E. Rossouw, G. L. Anderson, R. L. Prentice et al., "Risks and benefits of estrogen plus progestin in healthy postmenopausal women: principal results from the women's health initiative randomized controlled trial," The Journal of the American Medical Association, vol. 288, no. 3, pp. 321-333, 2002.

[4] T. S. Mikkola, P. Tuomikoski, H. Lyytinen et al., "Estradiolbased postmenopausal hormone therapy and risk of cardiovascular and all-cause mortality," Menopause, vol. 22, pp. 976-983, 2015.

[5] K. Zhou, Q. Gao, S. Zheng et al., "17 $\beta$-estradiol induces vasorelaxation by stimulating endothelial hydrogen sulfide release," Molecular Human Reproduction, vol. 19, no. 3, pp. 169-176, 2013.

[6] S. Worboys, D. Kotsopoulos, H. Teede, B. McGrath, and S. R. Davis, "Evidence that parenteral testosterone therapy may improve endothelium-dependent and-independent vasodilation in postmenopausal women already receiving estrogen," Journal of Clinical Endocrinology and Metabolism, vol. 86, no. 1, pp. 158-161, 2001.

[7] H. J. Garbán, G. M. Buga, and L. J. Ignarro, "Estrogen receptor-mediated vascular responsiveness to nebivolol: a novel endothelium-related mechanism of therapeutic vasorelaxation," Journal of Cardiovascular Pharmacology, vol. 43, no. 5, pp. 638644, 2004.

[8] Z. F. Ba and I. H. Chaudry, "Role of estrogen receptor subtypes in estrogen-induced organ-specific vasorelaxation after trauma-hemorrhage," American Journal of Physiology-Heart and Circulatory Physiology, vol. 295, no. 5, pp. H2061-H2067, 2008.

[9] R. Egami, Y. Tanaka, M. Nozaki, K. Koera, A. Okuma, and H. Nakano, "Chronic treatment with $17 \beta$-estradiol increases susceptibility of smooth muscle cells to nitric oxide," European Journal of Pharmacology, vol. 520, no. 1-3, pp. 142-149, 2005.

[10] Y.-W. Cheng and J.-J. Kang, "Mechanism of vasorelaxation of thoracic aorta caused by xanthone," European Journal of Pharmacology, vol. 336, no. 1, pp. 23-28, 1997.

[11] E. K. Naderali, S. L. Smith, P. J. Doyle, and G. Williams, “The mechanism of resveratrol-induced vasorelaxation differs in the mesenteric resistance arteries of lean and obese rats," Clinical Science, vol. 100, no. 1, pp. 55-60, 2001.

[12] G. Chen, L. Li, J. Zhang, and W. Mi, "The inhibitory effects of glibenclamide on propofol, ketamine, etomidate or midazolaminduced tracheodilation in isolated rabbit tracheal smooth muscle," The Journal of Clinical Anesthesiology, vol. 19, pp. 158160, 2003.

[13] V. M. Miller and S. P. Duckles, "Vascular actions of estrogens: functional implications," Pharmacological Reviews, vol. 60, no. 2, pp. 210-241, 2008.

[14] D. Xing, S. Nozell, Y.-F. Chen, F. Hage, and S. Oparil, "Estrogen and mechanisms of vascular protection," Arteriosclerosis, Thrombosis, and Vascular Biology, vol. 29, no. 3, pp. 289-295, 2009.

[15] A. Sobrino, P. J. Oviedo, S. Novella et al., "Estradiol selectively stimulates endothelial prostacyclin production through estrogen receptor- $\alpha$," Journal of Molecular Endocrinology, vol. 44, no. 4, pp. 237-246, 2010.

[16] T. Simoncini, C. Scorticati, P. Mannella et al., "Estrogen receptor $\alpha$ interacts with $\mathrm{G} \alpha 13$ to drive actin remodeling and endothelial cell migration via the RhoA/Rho kinase/moesin pathway," Molecular Endocrinology, vol. 20, no. 8, pp. 1756-1771, 2006.

[17] C. Filipe, L. L. S. Leen, L. Brouchet et al., "Estradiol accelerates endothelial healing through the retrograde commitment of uninjured endothelium," American Journal of Physiology-Heart and Circulatory Physiology, vol. 294, no. 6, pp. H2822-H2830, 2008.

[18] S. Chakrabarti, O. Lekontseva, A. Peters, and S. T. Davidge, " $17 \beta$-Estradiol induces protein S-nitrosylation in the endothelium," Cardiovascular Research, vol. 85, no. 4, pp. 796-805, 2010.

[19] C. L. Macêdo, L. H. C. Vasconcelos, A. C. de Correia et al., "Mechanisms underlying vasorelaxation induced in rat aorta by galetin 3,6-dimethyl ether, a flavonoid from Piptadenia stipulacea (Benth.) Ducke," Molecules, vol. 19, no. 12, pp. 1967819695, 2014.

[20] J. Zhu, L. Kang, Q. Ye et al., "Effects of Shenfu injection and its main components on the contraction of isolated rat thoracic aortic rings," PloS ONE, vol. 8, no. 10, Article ID e78026, 2013.

[21] H. Babaei and Y. Azarmi, "17 $\beta$-Estradiol inhibits calciumdependent and -independent contractions in isolated human saphenous vein," Steroids, vol. 73, no. 8, pp. 844-850, 2008.

[22] S. Sasmaz, A. S. Sahin, and I. Duman, "Inhibitory effect of fentanyl on phenylephrine-induced contraction on rabbit aorta," Pharmacol \& Pharmacy, vol. 2, pp. 141-145, 2011. 

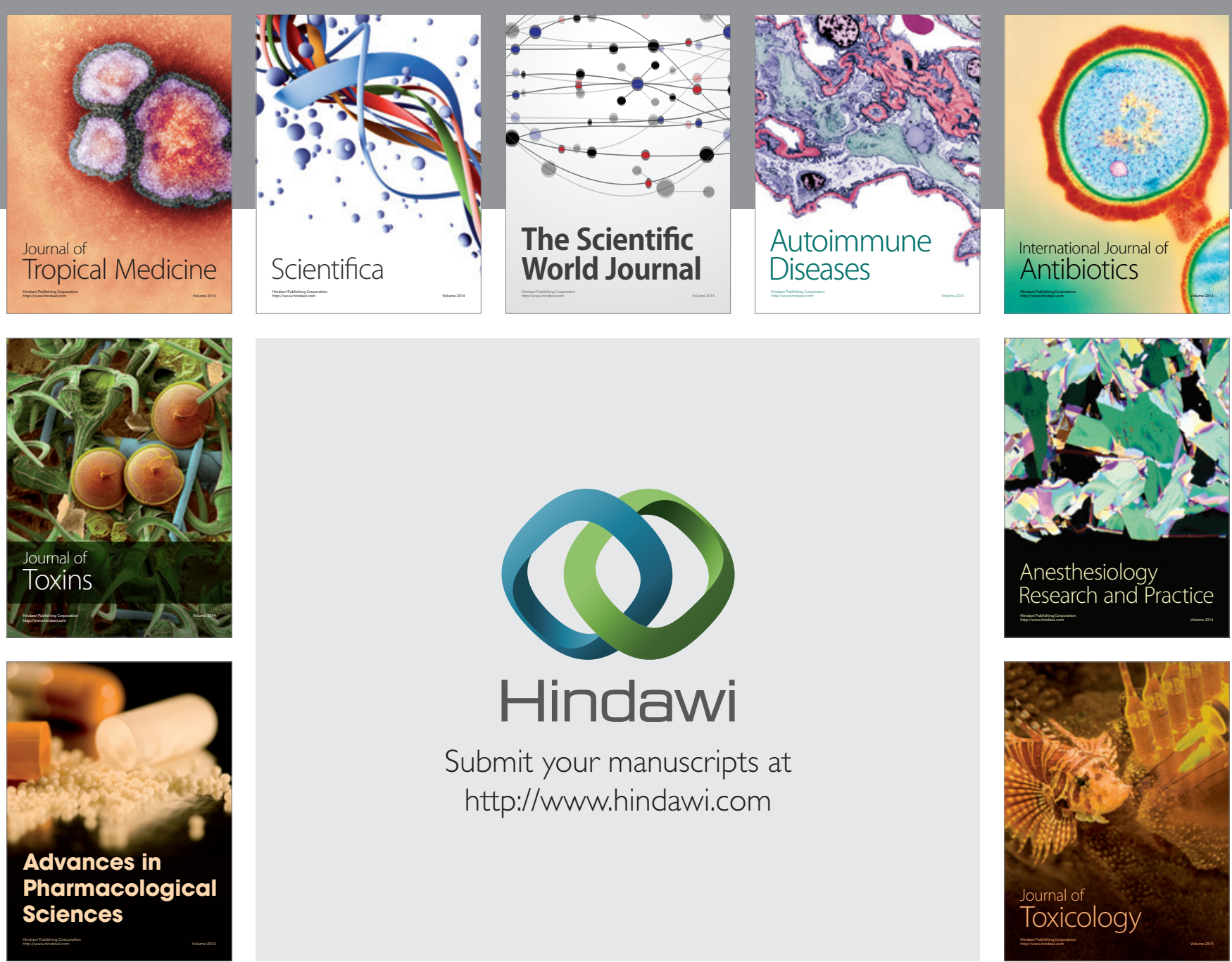

\section{Hindawi}

Submit your manuscripts at

http://www.hindawi.com
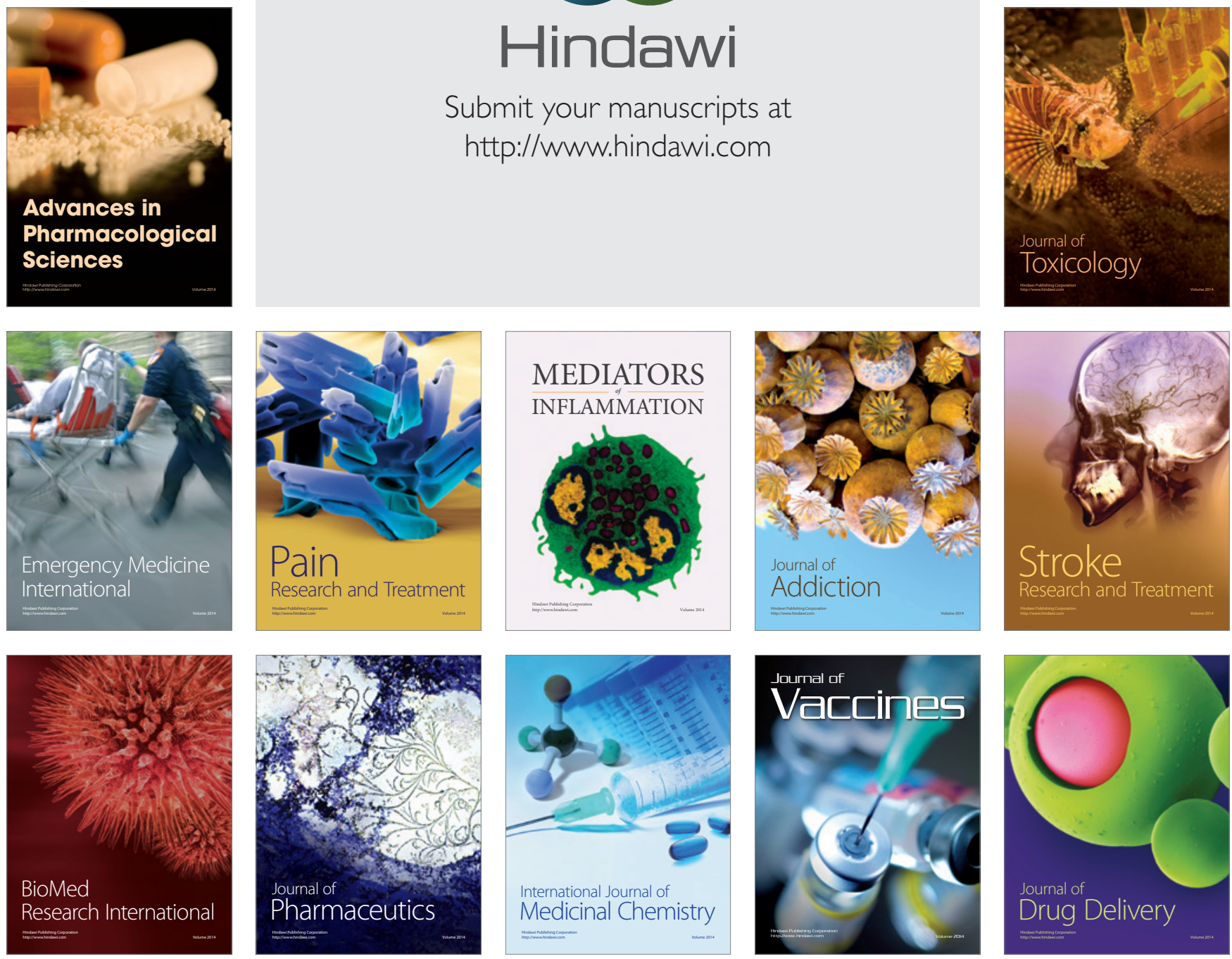